\title{
Estradiol-dependent Uterine Leiomyomas in Transgenic Mice
}

\author{
Béatrice Romagnolo, ${ }^{*}$ Thierry Molina, ${ }^{\ddagger}$ Guillaume Leroy, ${ }^{*}$ Claudine Blin, ${ }^{\S}$ Arlette Porteux, ${ }^{\star}$ Monique Thomasset, ${ }^{\S}$ \\ Alain Vandewalle, $\|$ Axel Kahn, ${ }^{*}$ and Christine Perret* \\ *Institut Cochin de Génétique Moléculaire (ICGM), INSERM U129, Faculté Cochin-Port Royal, 75014 Paris, France; ${ }^{\ddagger}$ Laboratoire \\ Universitaire de Recherche en Histopathologie de la Faculté Broussais-Hôtel Dieu, 75006 Paris, France; ${ }^{\circledR}$ INSERM U120, Hôpital Robert \\ Debré, 75019 Paris, France; and INSERM U246, Faculté de Médecine Xavier Bichat, Institut Fédératif de Recherche, \\ 75780 Paris Cedex 18, France
}

\begin{abstract}
Uterine leiomyomas are a major health problem for women of reproductive age. The molecular biology of these tumors is poorly understood partly because of the lack of relevant animal models. We have produced transgenic mice expressing the simian virus $40 \mathrm{~T}$ antigen driven by the promoter of the Calbindin-D9K (CaBP9K) gene and either $-1,000$ or $-117 \mathrm{bp}$ of regulatory sequences so as to establish in vivo, uterine smooth muscle tumor models. Six transgenic mouse lines were obtained. Leiomyomas developed in all of them, with an almost complete penetrance of the phenotype. The smooth muscle tumors arose in different parts of the female reproductive tract. Leiomyomas usually developed in the corpus of the uterus, but one mouse line developed leiomyomas in the horn of the uterus, and another in the vagina. The CaBP9K regulatory sequences directing the expression of the Tag gene possess an estradiol responsive element, and accordingly, development of the tumors was strictly under the control of estrogen. Expression of the Tag gene is not only necessary for the initiation of the tumor but also for its development and maintenance. These transgenic mouse models should be useful for studying the pathobiology of uterine leiomyomas and could be instrumental in designing new therapeutic approaches to this disease. (J. Clin. Invest. 1996. 98:777-784.) Key words: estrogens • Calbindin-D9K • uterine smooth muscle $\bullet$ tumor $\bullet$ SV40 T antigen
\end{abstract}

\section{Introduction}

Uterine leiomyomas are a major public health problem, since they occur in $>30 \%$ of women of reproductive age (1). Uterine leiomyomas are thought to be monoclonal tumors derived from a single myometrial cell $(2,3)$. But, progress toward a better understanding of the biology of leiomyomas and the development of new therapies for treating this disease has been slowed, in part, by the lack of a suitable in vivo model of the disease. Uterine leiomyomas are unique to woman. Models of uterine leiomyomas induced by either $\beta$-adrenergic agonists or long-term estrogen treatment have been developed in rodents;

Address correspondence to Christine Perret, INSERM U129, ICGM, Faculté Cochin-Port Royal, 24 Rue du Faubourg St. Jacques, 75014 Paris, France. Phone: 33-1-44-41-24-12; FAX: 33-1-44-41-24-21; E-mail: Perret@icgm.cochin.inserm.fr.

Received for publication 7 March 1996 and accepted in revised form 29 May 1996.

J. Clin. Invest.

(C) The American Society for Clinical Investigation, Inc.

0021-9738/96/08/0777/08 \$2.00

Volume 98, Number 3, August 1996, 777-784 however, these animals do not provide appropriate models for studying the molecular biology of the disease, because tumors arise infrequently, making these models not very convenient for experimental investigations (3, 4). A new Ecker rat model, in which reproductive tract leiomyomas arise spontaneously, has been described recently, but the tumors develop in only $30 \%$ of aged rats $>12$ mo old (5).

Transgenic mouse technology has proved very useful for creating new transgenic models of tumor development and providing systems for testing experimental therapeutic approaches (for reviews see references 6-8). Several transgenic mouse models of mammary cancer have been created (9-12), but no transgenic mouse suffering from uterine leiomyomas has so far been reported.

We have targeted the expression of the early region of simian virus $40(\mathrm{SV} 40)^{1}$ large tumor antigen (Tag) to the uterine myometrium of transgenic mouse using the $5^{\prime}$ flanking regions of the rat Calbindin D-9K (CaBP9K) gene (13). CaBP9K is found in several rat tissues, such as enterocytes, myometrium, and epithelial alveolar cells of the lung (14-17).The uterine $\mathrm{CaBP} 9 \mathrm{~K}$ gene is under the positive control of estradiol; the gene is silent in ovariectomized rodents $(18,19)$ and strongly activated after estradiol treatment $(20,21)$. CaBP9K is also expressed in the kidney of the mouse $(22,23)$. We analyzed the regulatory elements required for the tissue-specific expression of the rat $\mathrm{CaBP} 9 \mathrm{~K}$ gene in transgenic mice harboring hybrid transgenes in which reporter genes were directed by $\mathrm{CaBP} 9 \mathrm{~K}$ gene regulatory sequences. We showed that $-4,400$ bp of $5^{\prime}$ flanking sequences were necessary to target transgene expression in the intestine, $-1,011 \mathrm{bp}$ for expression in lung and kidney, and $-117 \mathrm{bp}$ for expression in the uterus (24). This report describes the phenotype resulting from the $\mathrm{CaBP} 9 \mathrm{~K}$-driven expression of SV40 Tag and the establishment of a transgenic mouse model of uterine leiomyomas. This model is inducible and the development of tumors is strictly under the control of estradiol.

\section{Methods}

Construction of hybrid genes. Transgenes were constructed by recombinant technology. The construction of the $9 \mathrm{~K} /-1011-\mathrm{Tag}$ and $9 \mathrm{~K} /-117-$ Tag constructs were prepared as follows. A fragment (from -22 to $+365 \mathrm{bp}$ ) containing the promoter region (beginning at the SacI site), the first exon, the first intron, and the beginning of the second exon (before the ATG initiation codon) was cloned by PCR. The resulting SacI-EcoRV fragment was then cloned, together with a fragment PstI-SacI containing 5 ' regulatory sequences of the rat CaBP9K gene (from $-1,011$ to $-22 \mathrm{bp}$ ) in the Bluescript KS vector. The 9K/-1011-Tag construct was obtained by inserting the Klenow-

1. Abbreviations used in this paper: SV40, simian virus 40; Tag, tumor antigen. 


\begin{tabular}{|c|c|c|c|c|c|c|c|c|c|c|c|c|c|}
\hline \multirow[b]{3}{*}{ Transgene } & \multirow[b]{3}{*}{ Lines } & \multirow{3}{*}{$\begin{array}{c}\text { Copy } \\
\text { number }\end{array}$} & \multicolumn{2}{|c|}{ Founder } & \multicolumn{3}{|c|}{ Tumors of uterine smooth muscle } & \multicolumn{3}{|c|}{ Lung adenocarcinoma } & \multicolumn{3}{|c|}{ Kidney polycystic disease } \\
\hline & & & & \multirow{2}{*}{$\begin{array}{c}\begin{array}{c}\text { Age of } \\
\text { death }\end{array} \\
\text { ology)* }\end{array}$} & \multicolumn{2}{|c|}{$\begin{array}{l}\text { Animal developing } \\
\text { tumors }\end{array}$} & \multirow{2}{*}{$\begin{array}{l}\text { Age in } \\
\text { months at } \\
\text { tumor } \\
\text { onset }\end{array}$} & \multicolumn{2}{|c|}{$\begin{array}{l}\text { Animals developing } \\
\text { tumors }\end{array}$} & \multirow{2}{*}{$\begin{array}{c}\text { Age in } \\
\text { months at } \\
\text { tumor } \\
\text { onset }\end{array}$} & \multicolumn{2}{|c|}{$\begin{array}{c}\text { Animals developing } \\
\text { tumors }\end{array}$} & \multirow{2}{*}{$\begin{array}{l}\text { Age in } \\
\text { months at } \\
\text { tumor } \\
\text { onset }\end{array}$} \\
\hline & & & & & Number & $(\%)$ & & Number & $(\%)$ & & Number & $(\%)$ & \\
\hline \multirow[t]{3}{*}{ PK/-1011-Tag } & 39 & 10 & $\mathrm{~F}$ & 9 & $17 / 17$ & $(100 \%)$ & 5 & $2 / 7$ & & 12 & $13 / 16$ & $(70 \%)$ & $6-12$ \\
\hline & $(\mathrm{LM}$ & -PCD) & & & & & & & & & & & \\
\hline & $\begin{array}{l}46 \\
(\mathrm{LI}\end{array}$ & $\begin{array}{r}2 \\
-A C)\end{array}$ & $\mathrm{F}$ & 9 & $6 / 10$ & $(50 \%)^{\ddagger}$ & 5 & $35 / 35$ & $(100 \%)$ & 3.5 & $0 / 2$ & & \\
\hline \multirow[t]{6}{*}{$9 \mathrm{~K} /-117-\mathrm{Tag}$} & 116 & 15 & M & 4 & $46 / 46$ & $(100 \%)^{\S}$ & 3 & & & & & & \\
\hline & 97 & 10 & $\mathrm{~F}$ & 9 & $19 / 19$ & $(100 \%)$ & 4 & & & & & & \\
\hline & \multicolumn{2}{|c|}{ (LM) } & & & & & & & & & & & \\
\hline & 121 & 5 & M & 4 & $4 / 4$ & $(100 \%)^{\|}$ & $3.5-5$ & & & & & & \\
\hline & 117 & 2 & $\mathrm{~F}$ & 9 & $2 / 6$ & $(20 \%)$ & 9 & & & & & & \\
\hline & & & & & & & & & & & & & \\
\hline
\end{tabular}

*LM, leiomyomas; PCD, polycystic kidney disease; AC, lung adenocarcinomas. ${ }^{\ddagger}$ The percentage of females which developed leiomyomas is probably underestimated, since all mice died before 8 mo of lung adenocarcinomas. ${ }^{8}$ In line $97,80 \%$ of the mice developed vaginal leiomyomas; the others developed leiomyomas in the corpus of the uterus. "Line 121 was difficult to breed, since most of the animals died before they were 1 mo old. Only four females survived up to 5 mo.

blunted 2.4-kbp StuI-BamHI fragment of the SV40 early gene containing only the large $\mathrm{T}$ coding sequence (small $\mathrm{t}$ sequences, from $-4,636$ to $-4,904 \mathrm{bp}$, were deleted) at the EcoRV site. The $9 \mathrm{~K} /-117-$ Tag construct was obtained by cloning together the SacI-EcorV fragment obtained by PCR cloning and containing the CaBP9K promoter region, with the HindIII-SacI fragment containing $5^{\prime}$ regulatory sequences of the CaBP9K gene (from -117 to $-30 \mathrm{bp}$ ) in the Bluescript KS vector. The coding region for the SV40 large T antigen was then inserted in the same way as for $9 \mathrm{~K} /-117-\mathrm{Tag}$.

Transgenic mice. The transgenes were separated from plasmid vector sequences by restriction endonuclease digestion and isolated by preparative agarose gel electrophoresis. The restriction fragments containing the chimeric gene were microinjected into fertilized mouse eggs as previously described (25). Founders were identified after Southern blot analysis of tail DNAs from 2-wk-old mice. Lines were established by outbreeding founder Fo mice to obtain heterozygous mice.

All mice were maintained in accordance with the "Ministère de l'Agriculture, de la Pêche et de l'Alimentation" guide for the care and use of laboratory animals (authorization number 04093, official Dr. Dominique Daegelen Proux).

Estrogen treatment of transgenic mice. Transgenic mice (5-6 wk old), carrying the $9 \mathrm{~K} /-1011$-Tag construct (lines 39 and 46), and the $9 \mathrm{~K} /-117-$ Tag construct (lines 97 and 116), were anesthetized and ovariectomized. 10 d later, each mouse was fitted with an Alzet minipump. The pumps delivered vehicle $(0.5 \mu \mathrm{l} / \mathrm{h})$ to the control group $\left(-E_{2}\right)$ and diethylstilbestrol $(100 \mu \mathrm{g} / \mathrm{kg})$ to the test mice $\left(+E_{2}\right)$ for $15 \mathrm{~d}$. The mice were then killed, and the uteri were removed and frozen in liquid nitrogen.

Northern blot and reverse transcriptase (RT)-PCR analyses. RNA was extracted from frozen tissue (up to $100 \mathrm{mg}$ ) by the Chomczynski procedure (26). Northern blot analyses were performed with $10 \mu \mathrm{g}$ RNA per deposit. Total RNAs were electrophoresed in $1.5 \%$ (wt/vol) agarose-formaldehyde gel and blotted on filters (21). Mouse CaBP9K mRNA was detected with a rat CaBP9K cDNA clone (15).Tag mRNA was detected with the StuI-BamHI fragment containing the coding region of the large $\mathrm{T}$ antigen.

The primers used for the RT-PCR analyses were oligonucleotides specific to the first exon of the rat CaBP9K gene (5'-TGTCTGACTCTGGCACGACT-3') and to the SV40 large T antigen (5'TAGTATGCCTTTCTCATCAGAGG-3') to detect Tag mRNAs.
Oligonucleotide primers specific to the dystrophin mRNA (upstream primer 5'-TAAAGCCTGTCCCCACT-3' specific to exon 75 , and downstream primer 5'-GGAAAGCCAATGAGAGA-3', specific to exon 78) were used as internal standards. The PCR products were electrophoresed, transferred to nylon membranes, and hybridized with specific probes.

Histology. Organs were fixed in Bouin's solution, dehydrated, and embedded in paraffin. Sections $(5 \mu \mathrm{m})$ were cut and stained with hematoxylin and eosin.

Immunohistochemical studies. The SV4O large T antigen was immunolocalized in uterine leiomyoma using a specific rabbit anti-large $\mathrm{T}$ antigen antibody (kindly provided by Dr. D. Hanahan, University of California, San Francisco). Frozen sections $(5-7 \mu \mathrm{m})$ were fixed with $2 \%$ paraformaldehyde at room temperature for $10 \mathrm{~min}$, incubated with $0.25 \%$ Nonidet P-40 (Boehringer Mannheim, Mannheim, Germany), rinsed in PBS, and incubated with the anti-large T antibody for $18 \mathrm{~h}$ at room temperature. After washing, samples were incubated with biotinylated anti-rabbit IgG and streptavidin-fluorescein (1:20, Vector Labs, Inc., Burlingame, CA). As controls, samples processed by omitting the anti-Tag antibody showed no labeling (not shown). Specimens were examined under a Zeiss photomicroscope equipped with epifluorescence optics and photographed.

\section{Results}

Tumorigenesis in CaBP9K/Tag transgenic animals. Two constructs were used to obtain transgenic mouse lines. The first 9K/-1011-Tag construct contained $-1,011$ bp of $5^{\prime}$ flanking sequences, the promoter region, the first intron, the first exon, and the beginning of the second exon of the CaBP9K gene linked to the coding sequence for Tag. The second 9K/-117Tag construct contained only $117 \mathrm{bp}$ of $5^{\prime}$ flanking sequences linked to Tag (24). Two pedigrees were obtained with the $9 \mathrm{~K} /$ -1011-Tag construct and four with the 9K/-117-Tag construct (Table I).

The founder of line 46 carrying the $9 \mathrm{~K} /-1011$-Tag construct was moribund at 9 mo of age. Analysis of this mouse shows many tumorous lung nodules which tended to be confluent in some place, and the loss of sufficient parenchyma for a 


\section{A $9 K /-1011-\mathrm{Tag}$}
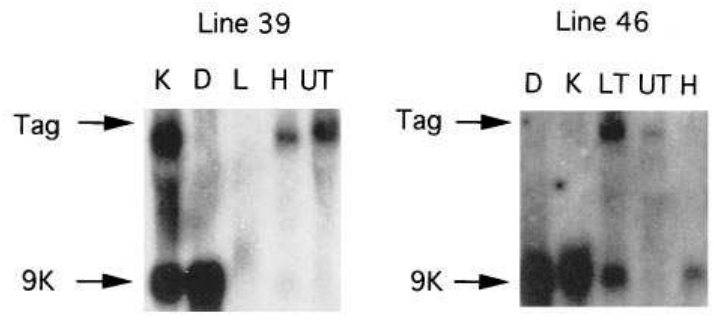

B $9 \mathrm{~K} /-117-\mathrm{Tag}$
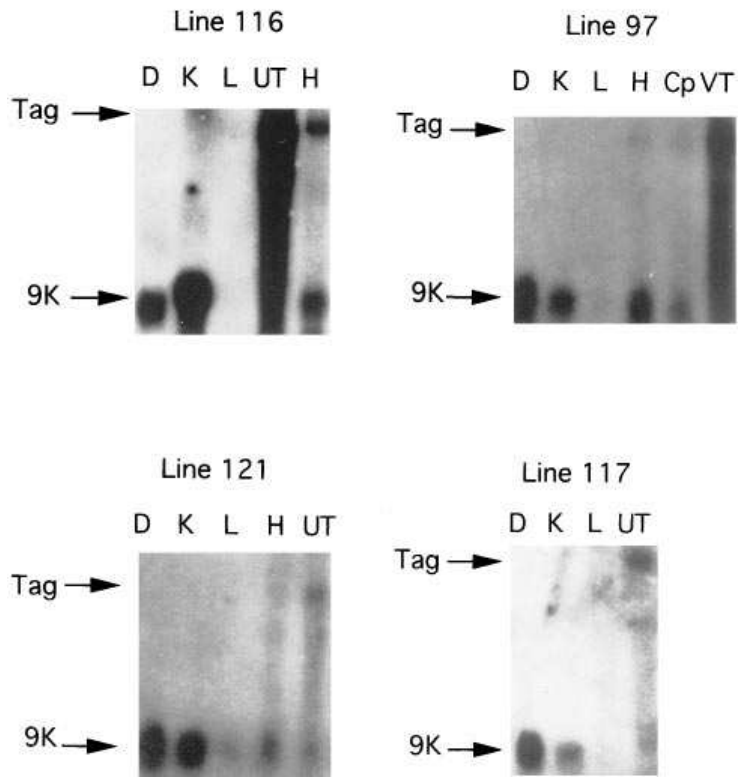

Figure 1. SV40 Tag expression in several tumor tissues. RNA was isolated from tissues of the transgenic mice and analyzed by Northern blot and hybridization with SV40 Tag (Tag) and CaBP9K (9K) probes. $(A)$ Northern blot of RNAs extracted from transgenic mice carrying the $-1011 /$ Tag construct. Line 39: $K$, kidney; $D$, duodenum; $L$, lung; $H$, horn of the uterus; $U T$, uterine tumor (uterine corpus). Line 46: $D$, duodenum; $K$, kidney; $L T$, lung tumor; $U T$, uterine tumor (corpus); $H$, horn of the uterus. ( $B)$ Northern blot of RNAs extracted from transgenic mice carrying the $-117 /$ Tag construct. Line 116: $D$, duodenum; $K$, kidney; $L$, lung; $U T$, uterine tumor (corpus); $H$, horn of the uterus. Line 97: $D$, duodenum; $K$, kidney; $L$, lung; $H$, horn of the uterus; $C p$, uterine corpus; $V T$, tumor of the vagina. Line 121: $D$, duodenum; $K$, kidney; $L$, lung; $H$, horn of the uterus; $U T$, uterine tumor (corpus). Line 117: $D$, duodenum; $K$, kidney; $L$, lung; $U T$, uterine tumor (corpus).

normal respiratory function was probably the reason for the distress of the animal. Analysis of the uterus showed enlargement of the corpus of the organ. Pathological studies indicated that the mouse had developed a lung adenocarcinoma and a uterine leiomyoma (Table I). The other founder for this construct (founder 39) had very few nodules in the lung, but had a large tumor in the corpus of the uterus. The female founders carrying the 9K/-117-Tag construct (founders 97 and 117) both developed uterine smooth muscle tumors. The tumor was localized in the corpus of the uterus of founder 117, and in the vagina of founder 97 . These tumors were uterine leiomyomas according to pathological criteria (Table I).

The offspring of these six transgenic mouse lineages all developed uterine leiomyomas. Most of the pedigrees showed a very high degree of penetration, since almost all the mice developed the disease (Table I). All the transgenic mice in line 46 developed lung adenocarcinomas, usually associated with uterine leiomyomas. In contrast, the transgenic mice of line 39 mainly developed polycystic kidney diseases, again always associated with uterine leiomyomas. Transgenic mice carrying the $9 \mathrm{~K} /-117-$ Tag construct developed uterine leiomyomas only.

Northern blot analysis was used to confirm that the pathology was associated with, and therefore most likely was due to, Tag expression. Fig. 1 shows the tissue distribution of the SV40 Tag mRNA in each lineage. Strong Tag gene expression was detected in pathological tissues in which lung adenocarcinomas, polycystic kidney disease, or uterine tumors developed.

Uterine smooth muscle tumor development. There was Tag expression in the myometrium of all 9K/-1011-Tag and 9K/ -117-Tag transgenic mice, regardless of the transgene integration site. However, there were marked differences between the six different lines of transgenic mouse that developed uterine leiomyomas (Table I). First, the tumors were located in different parts of the female reproductive tract in the different lines. Females of line 116 developed uniform, large (up to 18 grams) tumors in the corpus of the uterus (Fig. 2, $A$ and $B$ ). Females of lines 46, 117, and 121 had similar tumor phenotypes, but the tumors were smaller (never $>1$ gram) (Fig. 3 and data not shown). By contrast, $80 \%$ of the female mice of line $97 \mathrm{de}$ veloped vaginal leiomyomas (Fig. $2 C$ and Table I). The females of line 39 developed leiomyomas in the horn of the uterus; these tumors were pedunculate and located in one or both horns (Fig. $2 \mathrm{D}$ ). This development of uterine leiomyomas in different parts of the female reproductive tract was in agreement with the expression of the SV40 Tag gene analyzed by Northern blot or RT-PCR (Fig. 1 and see Fig. 6).

Second, as shown in Table I, the age at tumor onset varied from one line to another, line 116 had the shortest latency (2.5-3 mo), and lines 117-46 the longest (at least $6 \mathrm{mo}$ ). This was quite well correlated with the level of expression of the Tag gene (Fig. 2).

The development of the uterine tumors was monitored over several months in line 116 females. Uterine tumors developed 1 mo after puberty and grew with age (Fig. 3). The development of the tumors was rather variable, some mice had 12gram tumors at $4 \mathrm{mo}$, while others only had small tumors $(0.5$ grams) at 5 mo of age (Fig. 3).

To confirm that uterine leiomyomas were due to Tag expression, we performed immunohistochemical analysis. Tag expression was only detected in smooth muscle cells of the uterus (Fig. 4).

Leiomyoma histology. Histopathological analysis of a leiomyoma from a line 116 mouse revealed a proliferation of fusocellular smooth muscle cells from both layers of the myometrium to form whorls of anastomosing fascicles (Fig. 5, $A$ and $B$ ). The cytoplasm and nuclei appeared normal, but there were proliferation centers with a high mitotic index (Fig. $5 C$ ). The stroma was densely hyalinized, especially with older tumors (Fig. 5, $D$ and $E$ ). The tumors in the other lines were similar, with clear distortion of the myometrial wall in uterine horn tumors of line 39 mice (Fig. $5 F$ ). 


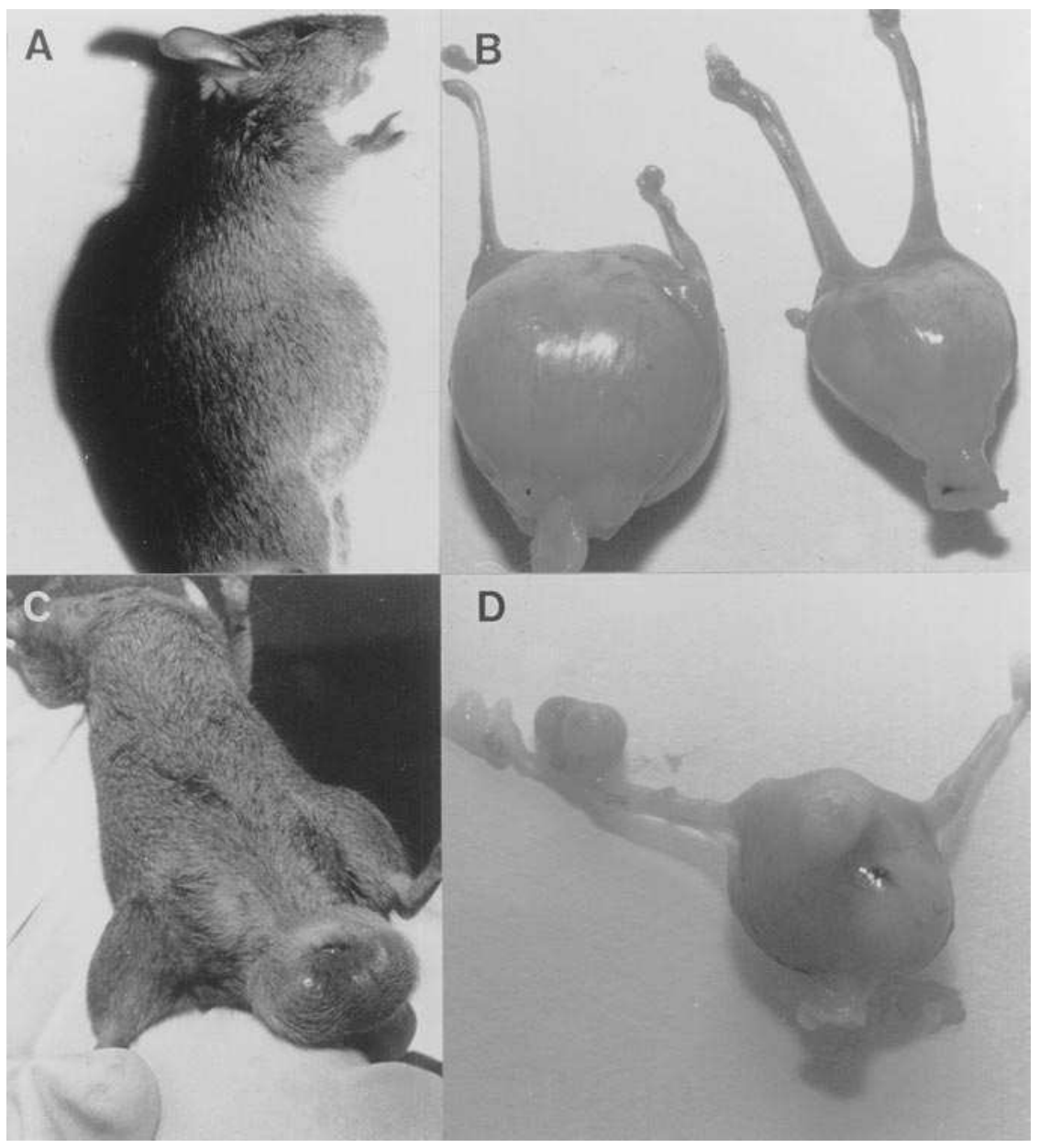

Figure 2. Morphology of the uterine tumors developed in $\mathrm{CaBP}-9 \mathrm{~K} / \mathrm{Tag}$ transgenic mice. $(A$ and $B$ ) Female mouse, line 116, aged 3-4 mo $(A)$, and its uterus $(B)$. Tumor lies in the corpus of the uterus. $(C)$ Transgenic mouse, line 97 , carrying a vaginal tumor. $(D)$ Uterine tumors of a transgenic mouse of line 39 . Note tumors in both the horn and corpus of the uterus.
There was never invasion of the peritoneum or destruction of the endometrium epithelium or metastasis even in older mice. Despite the high mitotic index in the tumors, which would be sufficient for a diagnosis of leiomyosarcoma in humans, there was never any local invasion or metastasis and, consequently, the tumors were classified as leiomyomas.

Estradiol dependence of the uterine leiomyomas. The $\mathrm{CaBP} 9 \mathrm{~K}$ regulatory sequences directing the expression of SV40 Tag contain an estradiol responsive element (27). The fact that the uterine leiomyomas developed only after puberty in females suggested that they were hormone responsive, probably via this estradiol responsive element. Mice of several transgenic lines were ovariectomized at puberty and uterine tumor development was monitored. No uterine tumors developed up to 7 mo after ovariectomy (Table II), indicating that these transgenic mice are good models of estrogen-dependent smooth muscle uterine tumors. The SV40 Tag expression analyzed by RT-PCR analysis was also hormone dependent (Fig. 6). SV40 Tag expression was not detected in the uterus of ovariectomized transgenic mice, but SV40 Tag expression was induced by estradiol treatment (Fig. 6). These results suggest that oncogene expression is needed for the initiation of the uterine tumor. To determine if the oncogene was also necessary for maintenance of the tumor, transgenic mice which had already developed uterine tumors were ovariectomized and changes in the tumor were monitored by MRI (Fig. 7). The tumors had not developed 1 mo after ovariectomy, and a rather weak regression could be observed, while the tumor in the nonoper- ated mouse continued to grow (Fig. 7 and see Fig. 3). The arrest of tumor growth, and even trend to regression, was confirmed in three other transgenic mice ovariectomized at different stages of tumor development (data not shown). The arrest of growth was associated with decreased mitotic activity in the tumor, suggesting that the high mitotic activity was due to the expression of the SV40 Tag gene (Fig. 7). The mitotic count per $10 \times \mathrm{HPF}$ (high power field) was 0 for ovariectomized transgenic mice versus 49 for the nonovariectomized transgenic mice. These results suggest that Tag expression was necessary not only for the initiation of the tumor, but also for its continuous development.

\section{Discussion}

The rat $\mathrm{CaBP} 9 \mathrm{~K} 5^{\prime}$ regulatory region has been used to direct the expression of the SV40 Tag gene to the uterine myometrium, thus providing transgenic models of uterine leiomyomas. The lines of transgenic mice were used to establish several models of leiomyomas of the female reproductive tract. The leiomyomas observed in transgenic mice were macroscopically and histologically similar to human tumors. Their growth was under the control of estradiol, which is also involved in the control of human myoma growth $(1,3)$. This makes the mouse model pertinent to address the mechanism controlling fibroid growth and morphology, and to investigate new nonsurgical therapeutic approaches of this common type of tumor. 


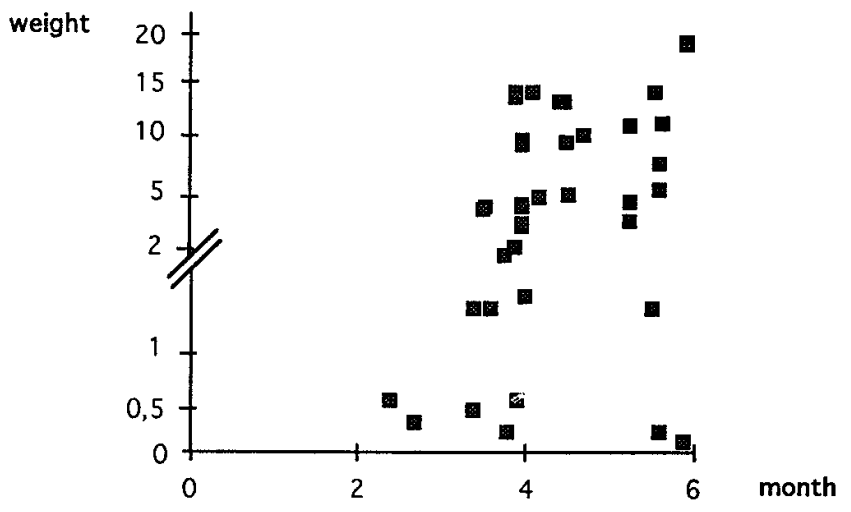

Figure 3. Development of the uterine tumor in transgenic mice of line 116. Transgenic mice (line 116) were killed at different ages (months) and their uterine tumors were weighed (grams). The uterus of a nontransgenic mouse weighs $<50 \mathrm{mg}$ (data not shown).

SV40 Tag is sufficient to perturb the growth properties of uterine myometrial cells. The age at onset of the tumor and the rapidity of their development seem to depend on the Tag level, but all of the mice developed uterine hyperplasia, which indicates that myometrial cells are sensitive to SV40 Tag-dependent proliferation. The lack of tumors in the uterine horns of line 116 mice carrying the $9 \mathrm{~K} /-117-$ Tag construct is interesting as the Tag gene is expressed in this part of the uterus. Perhaps a level critical to Tag synthesis is needed to induce proliferation of smooth muscle cells in this region of the uterus, and this level is not reached in line 116 females. Or, the myometrial cells of the horn of the uterus may be more resistant to tumorigenesis than the smooth muscle cells of the corpus. Results obtained with the rat Ecker model support the second alternative since leiomyomas arise more frequently in the corpus of the uterus (5).

As in the human tumors, the histological pattern of the leiomyomas developed in the transgenic mice showed zones of
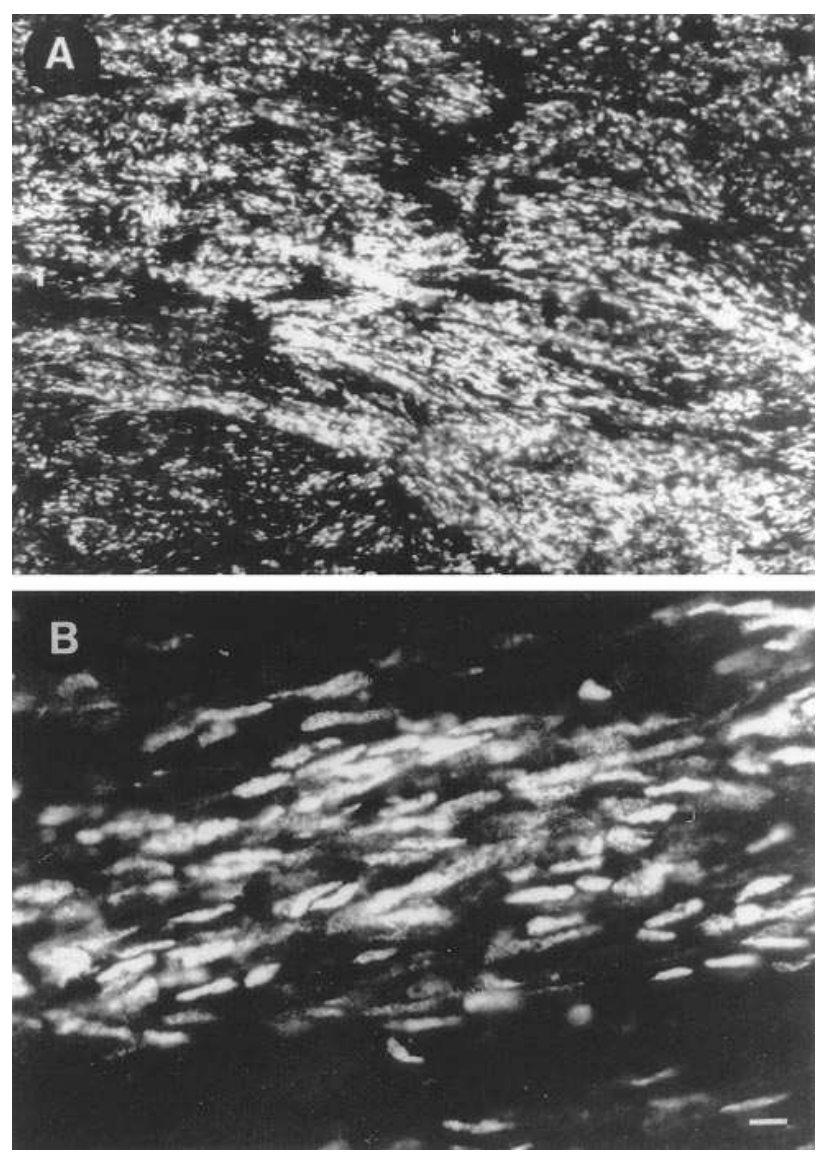

Figure 4. Pattern of large $\mathrm{T}$ antigen labeling in uterine leiomyoma. Frozen uterine leiomyoma sections were processed for indirect immunofluorescence using the anti-large $\mathrm{T}$ antigen antibody. Nuclear large $\mathrm{T}$ antigen positivity was detected in uterine smooth muscle cells $(A$ and $B)$. Note that the proliferative cells exhibiting an intense nuclear labeling $(A)$ are surrounded by arrays of less intense nuclear labeled and dispersed cells in hyaline stroma $(B)$. Bars: $A, 50 \mu \mathrm{m} ; B, 10 \mu \mathrm{m}$.
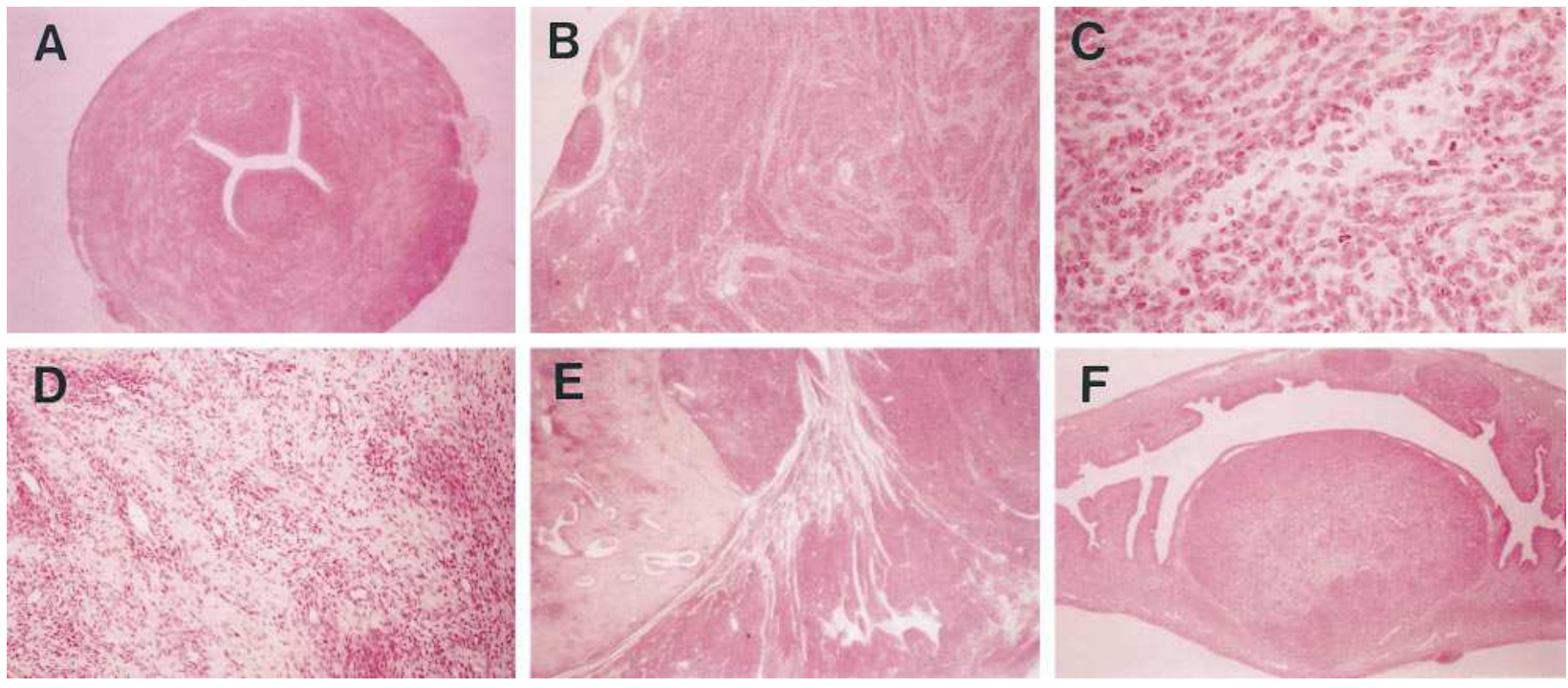

Figure 5. Histology of uterine tumors. (A) Section through uterine leiomyoma of line 116 mouse. Note the hypertrophy of the two layers of the myometrium. ( $B)$ Higher magnification, fascicles of spindle-shaped cells lying in a fibrous stroma. $(C$ and $D)$ Higher magnification. There are numerous mitosis among the proliferating myocytes without major cytonuclear atypia $(C)$ and regions with intense fibrous stroma $(D)$. $(E)$ Heterogeneous pattern of the tumor with areas of dense hyalinized fibrosis (left) and dense cell proliferation (right) in an old mouse. $(F)$ Uterus leiomyoma developing in the horn of a line 39 mouse, narrowing of lumen. 
Table II. Absence of Development of Uterine Leiomyomas in Ovariectomized CaBP/Tag Transgenic Mice

\begin{tabular}{lccccc}
\hline Reporter gene & Line & Number of mice & Age at ovx & Age at killing & Tumor \\
\hline 9K/-1011-Tag & 39 & 2 & 0.9 & 7 & No \\
& \multirow{2}{*}{46} & 2 & 1 & 7 & No \\
9K/-117-Tag & 116 & 12 & 1.7 & 3 & No \\
& \multirow{2}{*}{97} & 2 & 0.7 & 4 & No \\
& & 1 & 1.2 & 7 & No \\
& & 3 & 1 & 7 & No \\
\hline
\end{tabular}

intense cellularity interspersed with zones containing large amounts of noncellular matrix. Immunohistochemical studies have shown that the expression of SV40 Tag gene is uniform, and that all smooth muscle cells are labeled with anti-Tag. This indicates that SV40 Tag synthesizing smooth muscle cells have two types of response, intense proliferation or secretion of extracellular matrix. The factors involved in this dual decision are not known, but it is tempting to think that growth factors and/or their receptors are involved (28).

The strict hormone dependence of leiomyomas in these transgenic mice also mimics the situation in uterine myomas in women, in whom leiomyomas are estradiol dependent and tend to regress after menopause. The effects of estradiol on tu- mor cell growth may be mediated by the local production of growth factors. The dependence of tumor development on estrogen secretion in the $\mathrm{CaBP} 9 \mathrm{~K} / \mathrm{Tag}$ mice may have a twofold mechanism: estrogen-dependent Tag synthesis and the growthpromoting effects of estrogen itself on uterine smooth muscle cells. Our results clearly show that tumor development in these transgenic mice depends on Tag expression. However, estrogen could also be "permissive" for the SV40 Tag action, perhaps by stimulating its own growth-promoting genes or growth factor secretion, as suggested in other estrogen-dependent tumors like breast cancers (29). Consistent with this hypothesis, we found that the estrogen-dependent IGFI growth factor was overexpressed in growing leiomyomas and repressed by pure antiestrogens (Leroy, G., T. Molina, P. Fayet, B. Romagnolo, A. Vandewalle, A. Kahn, and C. Perret, manuscript in preparation). Human hormone-dependent cancers can evolve towards a stage of hormone independence. In breast cancers, this stage may be associated with posttranslational, ligand-independent activation of the estrogen receptor, resulting from a cross talk between growth factor signaling and the estrogen receptor (29-31). We have not seen this acquisition of estrogen independence for tumor growth in these transgenic mice models. Ovariectomy of transgenic mice bearing uterine leiomyoma results in the arrest of tumor growth. This indicates that cell proliferation remains dependent upon Tag synthesis throughout tumor development, without any evidence of autonomously growing cells which could result from the addition of secondary genetic events to Tag synthesis. However, estro-

\section{Line 39}

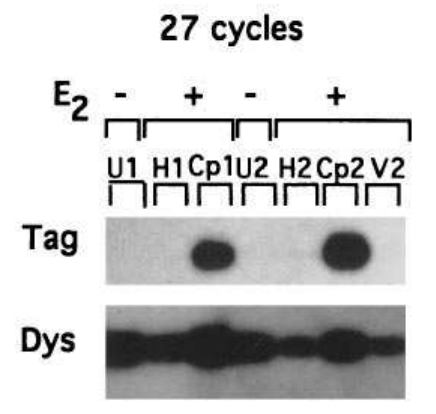

\section{Line 97}

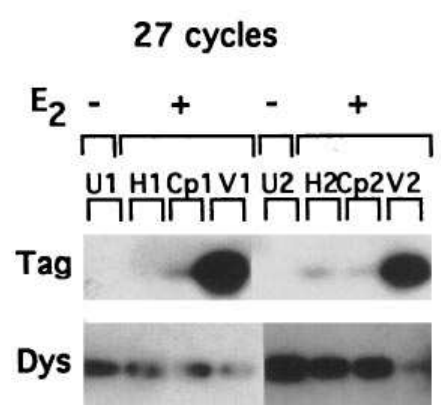

30 cycles

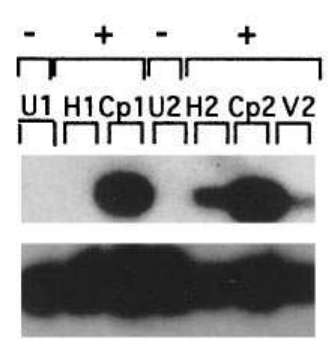

30 cycles

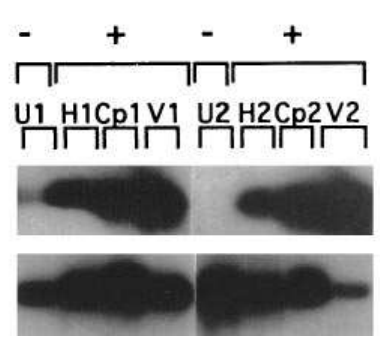

Line 46

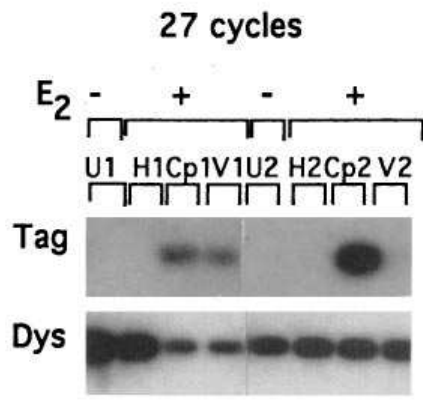

\section{0 cycles}

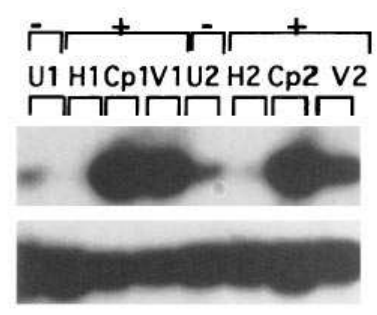

\section{Line 116}

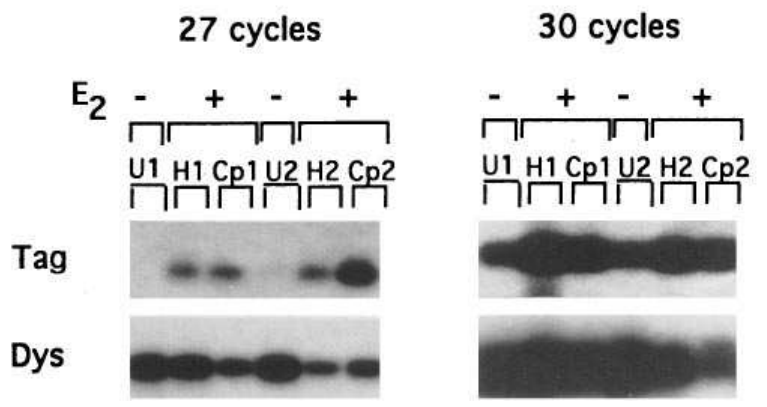

Figure 6. Control of SV40 Tag expression by estradiol in CaBP/Tag transgenic mice. Transgenic mice were ovariectomized at puberty and given vehicle $\left(-E_{2}\right)$ or diethylstilbestrol $(100 \mathrm{mg} / \mathrm{kg})\left(+E_{2}\right)$ via an Alzet mini-pump. RNAs were extracted and analyzed by RT-PCR for expression of the SV40 Tag gene (Tag); expression of the dystrophin gene (Dys) served as an internal control, since it is not controlled by estradiol. Products of RT-PCR were removed at 27 and 30 cycles and were analyzed by Southern blotting. Four mice from each transgenic line (lines 39, 46, 97, and 116) were used; two were given the vehicle $\left(-E_{2}\right)$ and RNA was extracted from the whole uterus ( $U 1$ and $\left.U 2\right)$; two were given estradiol ( $\left.+E_{2}\right)$ and RNA was extracted from the horn of the uterus $(H 1, H 2)$, the corpus of the uterus $(C p 1, C p 2)$, and the vagina $(V 1, V 2)$. 


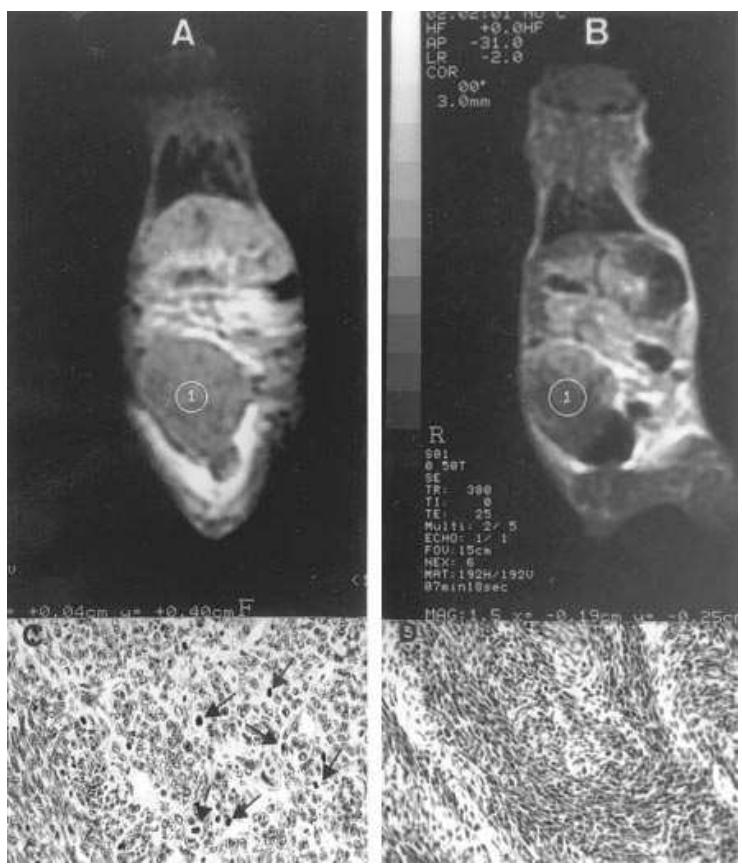

Figure 7. Dependence of uterine tumor development on SV40 Tag expression in $\mathrm{CaBP} / \mathrm{Tag}$ transgenic mice. The development of a uterine tumor in a transgenic mouse (line 116) was followed by MRI. The volume of the tumor in a 3.5 -mo-old mouse was measured $(A)$. The mouse was then ovariectomized and the size of uterine tumor was measured 1 mo later $(B)$. ( $C$ and $D$ ) Histology of the uterine tumor, before ovariectomy $(C)$ and 1 mo after ovariectomy $(D)$. There are no mitotic figures in $D$, but $C$ still has many (arrows).

gen-independent growth in vitro does occur. We have recently established a myometrial cell line from these transgenic mice which, like the original tumor, depends initially on estrogens for its growth (32). However, in later passages, cells proliferate without estradiol. Cells with an estrogen-independent growth phenotype constitutively expressed estrogen-responsive genes (e.g., Tag and $\mathrm{CaBP} 9 \mathrm{~K}$ genes). These genes are still inhibited by the pure antiestrogen ICI 182780 , indicating that like the phenomena of ligand-independent, posttranslational activation of estrogen receptor reported in some breast cancer cells (29-31), uterine estrogen receptor is still involved in estrogenindependent myometrial cell growth. The occurrence of this phenomenon in vitro, but not in vivo, could reflect genetic or epigenetic changes specific to continuous growth of smooth muscle cells in culture.

The uterine tumors developed in our transgenic mice are classified as benign tumors, since there was no nuclear atypia, local invasion, or metastasis, although the mitotic index was high. SV40 Tag seems to be sufficient to perturb the growth of smooth muscle cells, but not to fully transform them. In women, mitotic activity of uterine leiomyomas is believed to be an important indicator of malignancy and the distinction between leiomyoma and leiomyosarcoma is usually based on the mitotic index. In contrast, the high mitotic indexes of the murine leiomyomas described here seem to be insufficient to classify these tumors as malignant.

Since tumor development in the CaBP9K/Tag transgenic mouse remains dependent on Tag synthesis, it may require functional inhibition of the p53 and $\mathrm{Rb}$ antioncogenes, the products of which are known to bind to Tag (33). This mechanism is consistent with the frequent alterations in the p53 and $\mathrm{Rb}$ genes in human and rodent soft tissue sarcomas $(34,35)$. Heterozygosity for both p53 and Rb deficiencies, obtained by homologous recombination, leads to leiomyosarcoma development (36). Finally, rearrangement of the 12q13-14 chromosomal region has been described in human uterine leiomyomas $(3,37)$ and the Mdm-2 oncogene is located in this region. This may be significant because the Mdm-2 gene, the product of which binds $\mathrm{p} 53$, is amplified in many sarcomas $(38,39)$. Thus, the inhibition of p53 and (or) Rb functions seems to be an important factor in the tumorigenesis of smooth muscle cells.

In conclusion, the estrogen-dependent uterine leiomyomas that arise in these transgenic mice appear to be an appropriate model for studies on the pathobiology of these tumors which are very common in women. They could provide an appropriate system in which to develop new therapeutic approaches to this disease.

\section{Acknowledgments}

We thank Dr. J. Feuntun (IGR, Villejuif, France) for donating the vector coding for the SV40 large T antigen and Martine Douheret for help with the histology. We are indebted to Patricia Faillet (Service IRM, Hôpital Cochin, Paris, France) for the MRI imaging of the tumors and to Owen Parkes for the reading of the manuscript.

This work was supported by l'Institut Scientifique de Recherche Medicale (INSERM), "la Ligue Nationale Francaise contre le Cancer," and "l'Association pour la Recherche contre le Cancer" (ARC).

\section{References}

1. Rein, M.S., and R.A. Novack. 1992. Biology of uterine myomas and myometrium in vitro. Semin. Reprod. Endocrinol. 10:310-319.

2. Hashimoto, K., C. Azuma, T. Kamiura, T. Nobunaga, T. Kanai, M. Sawada, S. Noguchi, and F. Saji. 1995. Clonal determination of uterine leiomyomas by analyzing differential inactivation of the X-chromosome-linked phosphoglycerokinase gene. Gynecol. Obstet. Invest. 40:204-208.

3. Barbieri, L.R., and J. Andersen. 1992. Uterine leiomyomas: the somatic mutation theory. Sem. Reprod. Endocrinol. 10:301-309.

4. Fields, K.J., J.W. Griffith, and C.M. Lang. 1989. Spontaneous reproductive tract leiomyomas in aged guinea-pigs. J. Comp. Pathol. 101:287-294.

5. Everitt, J.I., D.C. Wolf, S.R. Howe, T.L. Goldsworthy, and C. Walker. 1995. Rodent model of reproductive tract leiomyomata. Clinical and pathological features. Am. J. Pathol. 146:1556-1567.

6. Hanahan, D. 1989. Transgenic mice as probes into complex systems. Science (Wash. DC). 246:1265-1275.

7. Adams, J.M., and S. Cory. 1991. Transgenic models of tumor development. Science (Wash. DC). 254:1161-1167.

8. Fowlis, D., and A. Balmain. 1993. Oncogenes and tumour suppressor genes in transgenic mouse models of neoplasia. Eur. J. Cancer. 29A:638-645.

9. Andrews, A.C., M.A. Van der Valk, C.A. Schonenberger, F. Flückiger, M. LeMeur, P. Gerlinger, and B. Groner. 1988. Ha-ras and c-myc oncogene expression interferes with morphological and functional differentiation of mammary epithelial cells in single and double transgenic mice. Genes Dev. 2:14861495.

10. Sinn, E., W. Muller, P. Pattengale, I. Tepler, R. Wallace, and P. Leder. 1987. Co-expression of MMTV/c-myc genes in transgenic mice. Synergistic action of oncogenes in vivo. Cell. 49:465-475.

11. Tsukamoto, A.S., R. Grosscheld, R.C. Guzman, T. Parslow, and H. Varmus. 1988. Expression of the int- 1 gene in transgenic mice is associated with mammary gland hyperplasia and adenocarcinomas in male and female mice. Cell. 55:619-625.

12. Matsui, Y., S.A. Halter, J.T. Holt, B.L.M. Hogan, and R.J. Coffey. 1990. Development of mammary hyperplasia and neoplasia in MMTV-TGF $\alpha$ transgenic mice. Cell. 61:1147-1155.

13. Perret, C., N. Lomri, N. Gouhier, C. Auffray, and M. Thomasset. 1988. The rat vitamin $\mathrm{D}$-dependent calcium-binding protein (9KDa $\mathrm{CaBP}$ ) gene. Complete nucleotide sequence and structural organization. Eur. J. Biochem. 172:43-51.

14. Thomasset, M., C.O. Parkes, and P. Cuisinier-Gleizes. 1982. Rat calcium binding proteins: distribution, development and vitamin D dependence. Am.J. 
Physiol. 6:E483-E488.

15. Perret, C., C. Desplan, and M. Thomasset. 1985. Cholecalcin (a 9-KDa cholecalciferol-induced calcium-binding protein) messenger RNA. Distribution and induction by calcitriol in the rat digestive tract. Eur. J. Biochem. 150:211217.

16. Warembourg, M., C. Perret, and M. Thomasset. 1986. Distribution of vitamin D-dependent calcium-binding protein messenger ribonucleic acid in rat placenta and duodenum. Endocrinology. 119:176-184.

17. Dupret, J.M., F. L'Horset, C. Perret, J.F. Bernaudin, and M. Thomasset. 1992. Calbindin-D9K gene expression in the lung of the rat. Absence of regulation by 1,25-dihydroxyvitamin D3 and estrogen. Endocrinology. 131:2643-2648.

18. Delorme, A.C., J.L. Danan, M.G. Acker, M.A. Ripoche, and H. Mathieu. 1983. In rat uterus $17 \beta$-estradiol stimulates a calcium-binding protein similar to the duodenal vitamin D-dependent calcium-binding protein. Endocrinology. 113:1340-1347.

19. Bruns, M.E., J.G. Overpeck, G.C. Smith, G.N. Hirsch, S.E. Mills, and D.E. Bruns. 1988. Vitamin D-dependent calcium binding protein in rat uterus: differential effects of estrogen, tamoxifen, progesterone, and pregnancy on accumulation and cellular localization. Endocrinology. 122:2371-2378.

20. L'Horset, F., C. Perret, A. Bréhier, and M. Thomasset. 1990. 17ß-estradiol stimulates the calbindin-D9K (CaBP9K) gene expression at the transcriptional and post-transcriptional levels in the rat uterus. Endocrinology. 127: 2891-2897.

21. L'Horset, F., C. Blin, A. Brehier, M. Thomasset, and C. Perret. 1993. Estrogen-induced calbindin-D9k gene expression in the rat uterus during the estrous cycle: late antagonistic effect of progesterone. Endocrinology. 132:489495.

22. Schreiner, D.S., V. Jande, C.O. Parkes, D.E.M. Lawson, and M. Thomasset. 1983. Immunocytochemical demonstration of two vitamin D-dependent calcium-binding proteins in mammalian. Acta Anat. 117:1-14.

23. Li, H., and S. Christakos. 1991. Differential regulation by 1,25-dihydroxyvitamin D3 of Calbindin-D9K and Calbindin-D28K gene expression in mouse kidney. Endocrinology. 128:2844-2852.

24. Romagnolo, B., F. Cluzeaud, M. Lambert, S. Colnot, A. Porteu, T. Molina, M. Thomasset, A. Vandewalle, A. Kahn, and C. Perret. 1996. Tissue-specific and hormonal regulation of Calbindin-D9K fusion genes in transgenic mice. J. Biol. Chem. In press.

25. Cuif, M.H., M. Cognet, D. Boquet, G. Tremp, A. Kahn, and S. Vaulont. 1992. Elements responsible for hormonal control and tissue specificity of L-type pyruvate kinase gene expression in transgenic mice. Mol. Cell. Biol. 12: 4852-4861.

26. Chomczynski, P., and M. Sacchi. 1987. Single step method of RNA isolation by acid guanidium thiocyanate phenol chloroform extraction. Anal. Biochem. 162:156-159.

27. L'Horset, F., C. Blin, S. Colnot, M. Lambert, M. Thomasset, and C. Per- ret. 1994. Calbindin-D9K gene expression in the uterus: study of the two messenger ribonucleic acid species and analysis of an imperfect estrogen-responsive element. Endocrinology. 134:11-18.

28. Cross, M., and T.M. Dexter. 1991. Growth factors in development, transformation, and tumorigenesis. Cell. 64:271-280.

29. Clarke, E., T. Skaar, K. Baumann, F. Leonessa, M. James, J. Lippman, E.W. Thompson, C. Farter, and N. Brunner. 1994. Hormonal carcinogenesis in breast cancer: cellular and molecular studies of malignant progression. Breast Cancer Res. Treat. 31:237-248.

30. Pietras, R.J., J. Arboleda, D.M. Reese, N. Wongvipat, M.D. Pegram, L. Ramos, C.M. Gorman, M.G. Parker, M.X. Sliwkowski, and D.J. Slamon. 1995. HER-2 tyrosine kinase pathway targets estrogen receptor and promotes hormone-independent growth in human breast cancer cells. Oncogene. 10:24352446.

31. Kato, S., H. Endoh, Y. Masuhiro, T. Kitamoto, S. Ushiyama, H. Sasaki, S. Masushige, Y. Gotoh, E. Nishida, H. Kawashima, et al. 1995. Activation of the estrogen receptor through phosphorylation by mitogen-activated protein kinase. Science (Wash. DC). 270:1491-1494.

32. Blin, C., F. L'Horset, B. Romagnolo, S. Colnot, M. Lambert, M. Thomasset, A. Kahn, A. Vandewalle, and C. Perret. 1996. Functional and growth properties of a myometrial cell line derived from transgenic mice: effects of estradiol and antiestrogens. Endocrinology. 137:2246-2253.

33. Fanning, E. 1992. Structure and function of simian virus 40 large tumor antigen. Annu. Rev. Biochem. 61:55-85.

34. Andreassen, A., E. Oyjord, E. Hovig, R. Holm, V.A. Florenes, J.M. Nesland, O. Myklebost, J. Hoie, A.L. Bruland, and O. Fodstadt. 1993. p53 ab normalities in different subtypes of human sarcomas. Cancer Res. 53:468-471.

35. Friend, S.H., J.M. Horowitz, M.R. Gerber, X.F. Wang, E. Bogenmann, F. Li, and R.A. Weinberg. 1987. Deletions of a DNA sequence in retinoblastomas and mesenchymal tumors: organization of the sequence and its encoded protein. Proc. Natl. Acad. Sci. USA. 84:9059-9063.

36. Williams, B.O., L. Remington, D.M. Albert, S. Mukai, T.R. Bronson, and T. Jacks. 1994. Cooperative tumorigenic effects of germline mutations in Rb and p53. Nat. Genet. 7:480-484.

37. Fotidou, S.K., A.J. Tserkezoglou, H. Mahera, A.E. Konstandinidou, N.J. Agnantis, N. Pandis, and G. Bardi. 1992. Chromosome aberrations and expression of ras and myc oncogenes in leiomyomas and a leiomyosarcoma of the uterus. Eur. J. Gynaecol. Oncol. 13:340-345.

38. Leach, F.S., T. Tokino, P. Meltzer, M. Burrell, J.D. Oliner, S. Smith, D.E. Hill, D. Sidransky, K.W. Kinzler, and B. Volgestein. 1993. p53 mutation and MDM2 amplification in human soft tissue sarcomas. Cancer Res. 53:22312234

39. Olinern, J.D., K.W. Kinzler, P.S. Meltzer, D.L. George, and B. Vogelstein. 1992. Amplification of a gene encoding a p53-associated protein in human sarcomas. Nature (Lond.). 358:80-83. 